\title{
15. Fertility desires, intentions, and behaviour
}

\author{
Ann Berrington
}

\section{EUROPEAN FERTILITY TRENDS}

In almost all high-income countries, period fertility rates are well below the replacement level of 2.1 births per woman, which is the average number of births required to replace one generation with another in the absence of migration. But there are significant differences between and within countries in childbearing behaviour, in terms of both the timing of entry into parenthood and completed family size (Mills et al. 2011). In this chapter, we focus on Europe, where fertility rates (as measured by the period total fertility rate (TFR)) increased during a 1960s baby boom, and then fell significantly, to either low or lowest low (less than or equal to 1.3 births per woman) levels. Figure 15.1 presents the trends for a number of selected countries to show the diversity across Europe, and to include a variety of geographical regions. In Northern and Western Europe, fertility rates fell during the 1970s as individuals started to postpone the age at which they became parents, and to reduce their overall number of children. The rising mean age at first birth (Figure 15.2) and increased childlessness were part of a broader wave of changes in family formation (including delays in partnership formation, declines in marriage, and increases in separation) that led to the coining of the term 'the Second Demographic Transition' (Lesthaeghe 1995). The decline in fertility rates took place later on in Southern European countries, including in Spain, where the TFR fell from 2.2 births per woman to 1.3 births per woman within a single decade (1982-92).

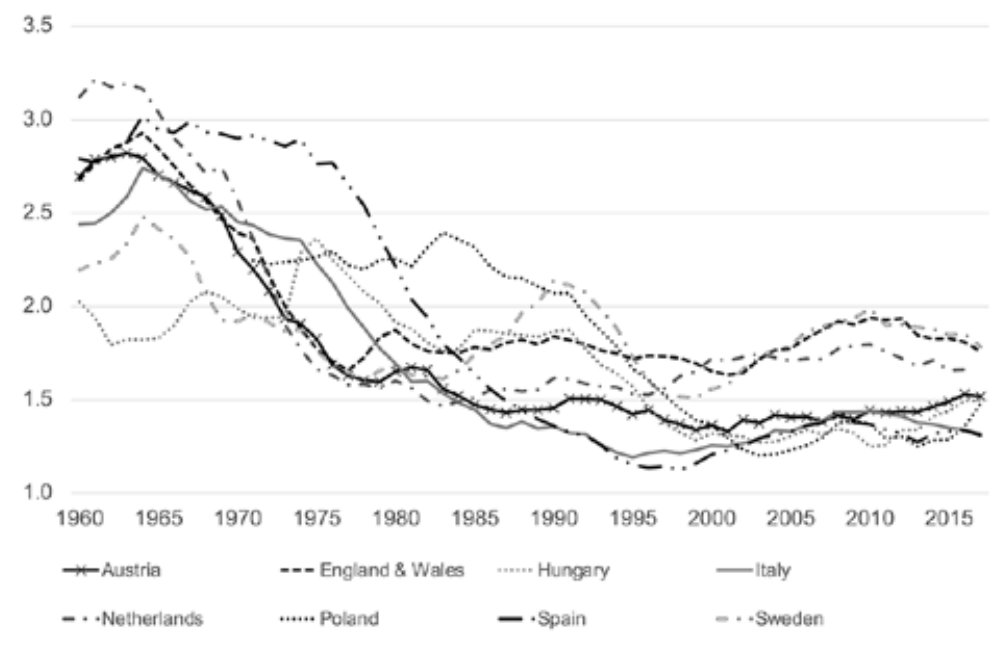

Source: Eurostat (2019); HFD (2019).

Figure 15.1 Total fertility rate in selected European countries 1970-2017 
Lowest low fertility spread rapidly within Europe during the 1990s. In many Eastern European countries, fertility rates dropped following the collapse of socialism, partly as a result of tempo distortions in the TFR. These distortions occurred because young adults were postponing childbearing, partly in response to increased economic uncertainty and delays in the age at leaving full-time education (Kohler et al. 2002), but also because various institutional and financial supports for high fertility that were provided during the socialist era had been removed.

The interpretation of the socio-economic and cultural drivers of lowest low fertility is complicated by the fact that period rates of fertility such as the TFR can be affected by tempo distortions in childbearing behaviour - i.e., by changes among cohorts in the ages at which childbearing takes place (Bongaarts and Feeney 1998). Generally, when childbearing starts to be postponed (delayed to later ages) among young cohorts, period indices of fertility are depressed; and when cohorts recuperate (catch up) their fertility at older ages, the TFR rises once again. Thus, it is possible for a population to maintain a steady completed family size of an average of two births per woman, but still exhibit substantial fluctuations in fertility. However, period fertility rates have been significantly below replacement level for over three decades in countries such as Austria, Germany, Italy, and Spain, and are thus associated with significant declines in completed family size. Completed family size, or cohort fertility, refers to the average number of children women will give birth to by age 45 . Low average completed family size at a population level can be achieved in different ways, depending upon how many women end up with zero, one, two, three, or more births. By examining parity-specific trends, recent research has shown that the route to lowest low fertility has differed regionally in recent decades (Zeman et al. 2018). In Southern Europe, levels of fertility postponement have been pronounced (Figure 15.2), and levels of childlessness have increased significantly.

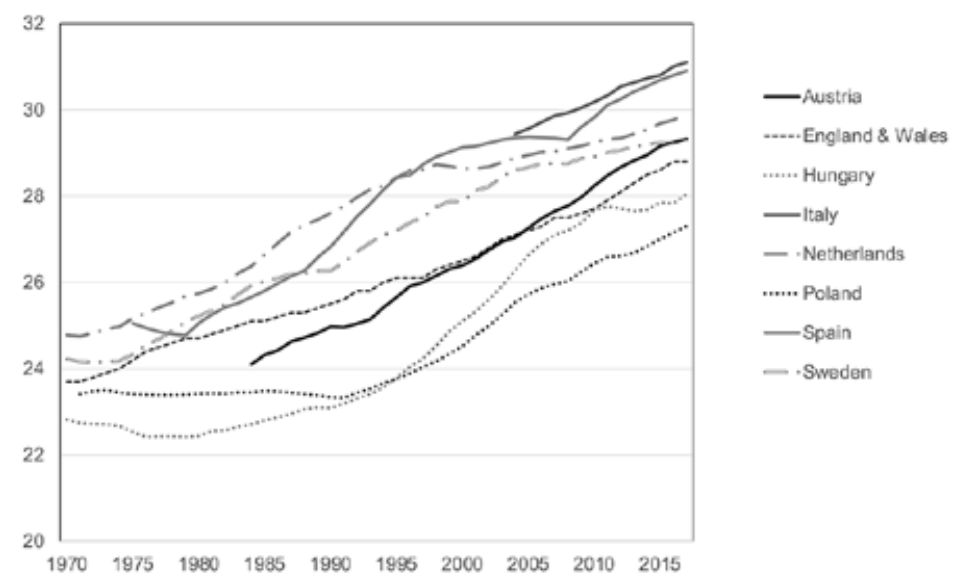

Source: Eurostat (2019); HFD (2019); ONS (2017).

Figure 15.2 Mean age at first birth in selected European countries, 1970-2017

In Eastern Europe, entry into motherhood generally takes place at slightly younger ages, but there has been a marked decrease in second birth rates, with one-child families becoming 
more prevalent. In Northern and Western Europe, there has been a more modest postponement trend, and more evidence of fertility recuperation. Starting in the late 1990s, a clear polarisation within Europe emerged in which many Northern and Western European countries had TFRs of around 1.7-1.9, whereas many Central (e.g., Austria), Southern, and Eastern European countries had fertility rates of 1.3 or lower.

During the early 2000s, period fertility rates increased in many countries. But since 2010, the trends have been more mixed, with Northern and Western countries exhibiting decreases in period fertility at the same time as many Southern and Eastern countries have been experiencing increases. These developments have resulted in a slight convergence of levels around 1.4-1.7 births per woman. Increases in period fertility in some Eastern European countries such as Hungary are likely to be associated with the slowing down or cessation of postponement. However, no such recovery in period fertility is apparent in Spain, where the mean age at first birth has continued to increase to reach an average of 30.9 in 2017 (Figure 15.2).

\section{IDEAL FAMILY SIZE AND THE FERTILITY GAP}

Even as fertility rates have been declining, the stated ideal family size preferences of women in most European countries have remained near or above replacement level (Goldstein et al. 2003; Sobotka and Beaujouan 2014; Testa 2012). ${ }^{1}$ This disparity between aggregate fertility desires and achieved fertility has been described as a 'fertility gap' (Philipov 2009) or an 'unmet demand for children' (Brinton et al. 2018). In the context of rapid population ageing caused in part by declines in fertility rates, evidence of a 'fertility gap' was enthusiastically embraced by European policy-makers who assumed that if the right family policies were implemented, people would be able to have the number of children they wanted (Philipov 2009). To inform the development of such policies, academic researchers intensified their efforts to use individual data to investigate the reasons why fertility intentions often remain unrealised. A number of theoretical frameworks were developed and applied, including the European Union 7th Framework Funded REPRO project (Liefbroer et al. 2015), which is discussed in more detail in the next section.

The 'fertility gap' concept has been critiqued on a number of grounds (Goldstein et al. 2003). First, it has been suggested that responses to questions relating to ideal and desired fertility merely reflect existing societal norms (e.g., for a two-child family). Other scholars have questioned whether individuals have sufficient information about their future ability to reproduce or their socio-economic circumstances (Westoff and Ryder 1977) to anticipate their ideal family size. Thus, these scholars have argued that childbearing decisions are not fixed, but are, rather, made sequentially. This concept has also been critiqued on methodological grounds. It has, for example, been pointed out that the usual way in which the 'fertility gap' is constructed - e.g., from cross-sectional Eurobarometer Survey data - does not compare the fertility desires and behaviour of the same cohorts of women, but instead compares the intentions of women currently having children with the achieved fertility of past cohorts (Beaujouan and Berghammer 2019). Furthermore, we cannot infer relationships between desires and fertility outcomes at the individual level from macro-level analyses. Studies using individual longitudinal data have found that some women underachieve and some overachieve their earlier stated desires and intentions (Berrington 2017; Berrington and Pattaro 2014; Morgan and Rackin 2010; Quesnel-Vallée and Morgan 2003). These important criticisms of 
this research notwithstanding, the existence of the 'fertility gap' led to renewed interest in the 2000 s in identifying the factors that affect the realisation of fertility desires and intentions. In the rest of this chapter, we review some of the key theoretical approaches and findings from this work, and suggest some ideas for future research.

\section{THEORETICAL APPROACHES TO UNDERSTANDING FERTILITY INTENTIONS AND THEIR REALISATION}

A number of different theoretical approaches, each with different emphases, have been used to examine the link between fertility desires, intentions, and fertility outcomes. Miller's Traits-Desires-Intentions-Behaviour (TDIB) model (Miller 1994), shown in Figure 15.3, assumes that individuals have motivational traits (which could be genetic or psychological in origin) that endure over time. 'During growth and development, biologically based, largely hereditary characteristics of the individual interact with the individual's childhood and adolescent social environments, leading to the formation of a motivational substrate for childbearing' (Miller et al. 2010, p 394). While these motivations are generally not observed, when they are activated, they are experienced as childbearing desires. It is not until the perceived situational constraints are assessed - e.g., an individual's partnership status or employment situation - that desires are converted into intentions. Intentions imply some degree of personal commitment to act, albeit within an unspecified time frame (Miller 1994). The TDIB model has been used together with behavioural genetic analyses of siblings in the National Longitudinal Study of Youth in order to demonstrate the importance of genetic precursors to fertility motivations, which then act through desires to influence intentions, and ultimately influence outcomes (Miller et al. 2010). The TDIB model is sometimes avoided because of its demanding data requirements. It has, however, provided new insights in cases in which detailed prospective information was available. For example, the 1958 British Birth Cohort Study (Berrington and Pattaro 2014) followed

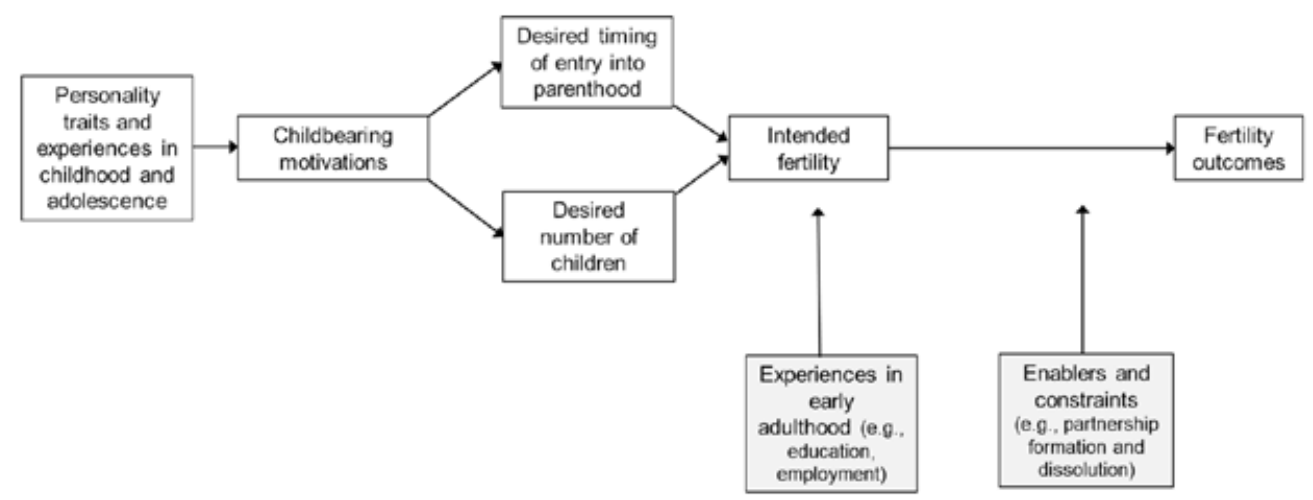

Source: Own representation based on Miller (1994).

Figure 15.3 Traits-Desires-Intentions-Behaviour framework 
up participants from birth to age 46, collecting detailed information on their parental fertility trends, childhood circumstances, fertility desires in adolescence (at age 16), and intentions in adulthood (at age 23).

Berrington and Pattaro (2014) found that parental characteristics (e.g., maternal age at first birth) and socialisation in childhood (e.g., sibling group size, parental expectations for the respondent's education) affected the desired timing of family formation differently than they affected the desired number of children. Consistent with the TDIB framework, family size intentions reported at age 23 were revised downwards in young adulthood as individuals experienced more of life, entered the labour market, and saw for themselves the economic and non-economic opportunity costs that childbearing entailed. Mean completed family size at age 46 (1.76 for men and 1.91 for women) was significantly lower than intended family size reported at age 23 (2.23 for men and 2.30 for women). In total, just 36 per cent of men and 43 per cent of women had achieved their intended number of children, with those who wished to remain childless and those who wanted to have two children being the most likely to have realised their fertility intentions. Consistent with evidence from the United States (US) (Morgan and Rackin 2010; Quesnel-Vallée and Morgan 2003), the analysis showed a tendency to underachieve fertility intentions, especially among those who originally intended to have a larger family.

The Theory of Planned Behaviour (TPB) is a general theory that has been developed within social psychology (Ajzen 1991), and has been applied to a wide range of issues, including fertility behaviour (Liefbroer et al. 2015) (Figure 15.4). The TPB makes explicit that an individual's context can affect his/her intentions through the formation of attitudes (e.g., relating to the advantages and disadvantages of having children), subjective norms (e.g., social influences exerted by significant others, such as parents and friends), and the individual's perceived behavioural control. These conditions can, in turn, influence the extent to which the individual's intentions are realised. Moreover, the TPB specifically acknowledges factors that may either enable or constrain an individual from carrying out his/her intentions, such as the availability of child care. A large number of empirical analyses of both fertility intentions (e.g., Billari et al. 2009; Dommermuth et al. 2011; Klobas and Ajzen 2015) and their realisation (e.g., Riederer et al. 2019; Spéder and Kapitány 2015) at the individual level using TPB have been carried out over the past decade. These studies often used data from the Generations and Gender Surveys (GGS), which included a special adaptation of the TPB for use in studying fertility decisions. The GGS focus on a short time horizon, such as on the respondents' intentions to have a birth now, or within three years. This body of work has found that while attitudes, subjective norms, and perceived control all play an important role in the formation of intentions, the relationships between these influences differ by country, age, and current parity, which makes formulating policies to reduce the 'fertility gap' complex (Klobas et al. 2015). In Norway, for example, Dommermuth et al. (2011, p. 42) found that subjective norms influenced intentions, as those respondents who expressed confidence that their intention to have a child was supported by their friends and family were more likely to want to have a child now, rather than within the next three years. Furthermore, the respondents' perceived ability to cope with having a child (deemed a proxy for behavioural control) was also shown to be associated with positive intentions. Billari et al.'s (2009) analyses of Bulgarian GGS data suggest that economic constraints and the ability to form a partnership were key factors affecting perceived behavioural control, and contributed to lower fertility; but also that attitudes played a larger role than norms in intentions to have higher-order births. The TPB is a useful tool for 
understanding the interactions between the macro and the micro levels (Klobas and Ajzen 2015). Brinton (2016) used the TPB and data from a number of GGS countries - some with moderate levels of fertility (e.g., France, Norway) and some with very low levels of fertility (e.g., Austria, Hungary, Italy) - to show how social norms and institutional arrangements affect perceived barriers to childbearing. She found that in countries with gender-essentialist family roles (male breadwinner, female caregiver), individuals reported greater financial barriers to childbearing, and particularly concerns relating to housing and childcare. She also argued that the cultural or institutional context can moderate the impact of economic uncertainty on childbearing. Thus, in Southern Europe, the prevalence of traditional gender role attitudes meant that childbearing was only considered possible when the male partner was able to fulfil a breadwinning role.

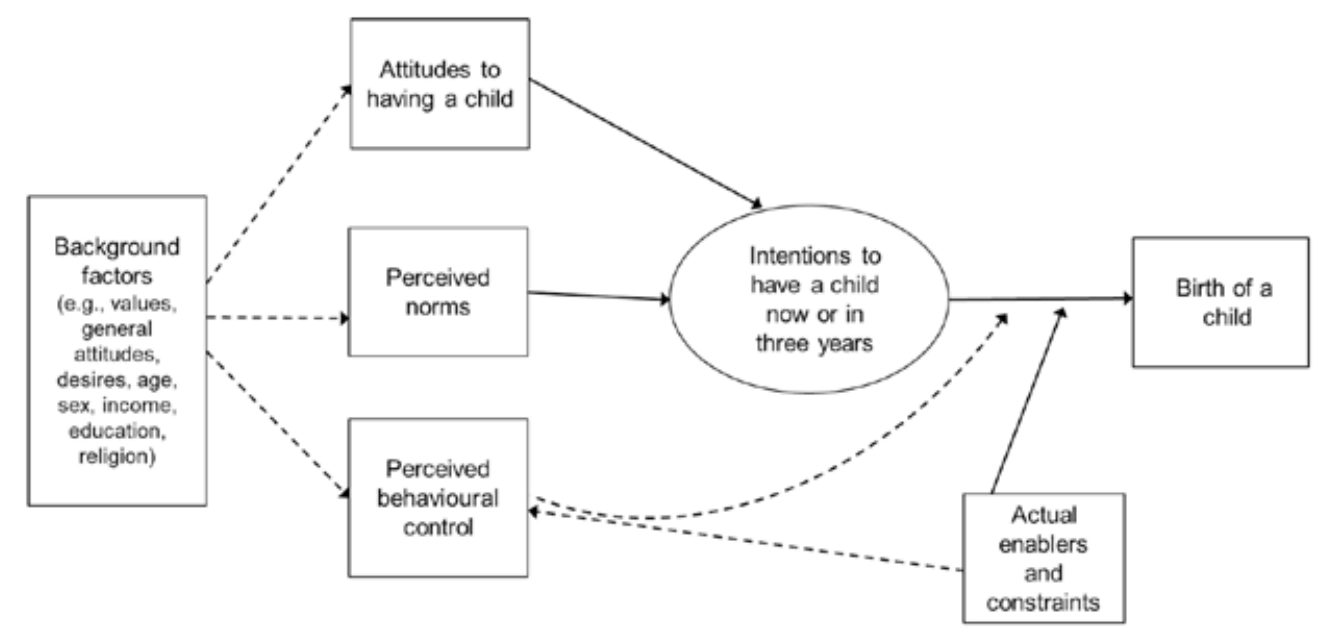

Source: Own representation based on Dommermuth et al. (2011).

Figure 15.4 Theory of Planned Behaviour applied to fertility

The TPB focuses on reasoned action. More recently, demographers have developed the Theory of Conjunctural Action (Johnson-Hanks et al. 2011) and the Cognitive Social Model (CSM) of fertility intentions, which combine ideas from cognitive science with insights about social structure from social theory (Bachrach and Morgan 2013). CSM differs from the previous two theories in that it does not stipulate that conscious intentions must precede behaviour, but instead suggests that fertility behaviour is the result of both conscious, deliberative intentions and non-deliberative, automatic cognitions. These cognitions are hypothesised to derive from social structures that are themselves composed of both material (observable) structures and schemas (abstract representations of the meaning of an object or event) (Johnson-Hanks et al. 2011). For example, depending on their gender, age, income, and geographical location, individuals are more or less likely to be exposed to or to identify with particular structures (and their material and schematic components). Schemas are not fixed, but are instead shaped by background factors, experiences, and life course transitions, such as becoming a parent or starting a new job (Bachrach and Morgan 2013). Thus, the CSM explicitly acknowledges 
that fertility intentions will change across the life course, and considers the potential sources of these changes, which are likely to include life course transitions (Rybińska and Morgan 2018). Moreover, the CSM argues that fertility intentions are formed only when the 'circumstances of a situation demand or motivate it' (Bachrach and Morgan 2013, p. 468). The idea that intentions are constructed rather than retrieved is also emphasised by Ni Bhrolcháin and Beaujouan (2019), who suggested that fertility intentions are assembled when individuals are asked to report a preference, and that these preferences are constructed through personal experiences and life choices, observations of the family formation patterns of peers, and the influence of societal norms. These authors hypothesised that preferences crystallise over time. 'From repeated exposure to reproductive choices, to the wishes of a partner, to the practicalities of family formation, of housing, of combining family and economic activity, people will ultimately arrive at clearer preferences, though these need not be very well articulated and may retain a constructive element' (Ni Bhrolcháin and Beaujouan 2019, p. 43). Thus, arguably, the CSM more closely reflects the real-life experiences of childbearing, including unintended fertility, than comparable models. It does not assume that individuals are able to accurately predict their future circumstances, and allows for changes in intentions across the life course (Ni Bhrolcháin and Beaujouan 2019; Rackin and Bachrach 2016). The CSM is less exact than either the TDIB or the TPB models in pre-determining the factors that affect childbearing decisions (and can therefore be used to analyse a wide variety of quantitative and qualitative data).

The CSM is consistent with numerous empirical studies that have highlighted the uncertainty in reported intentions (Berrington 2004; Morgan 1981; Ni Bhrolcháin and Beaujouan 2019; Trinitapoli and Yeatman 2018); changes in intentions, particularly during the early life course (Berrington and Pattaro 2014; Hayford 2009; Iacovou and Tavares 2011; Liefbroer 2009; Rybińska and Morgan 2018); and the mismatch between stated intentions and fertility outcomes (Berrington 2017; Quesnel-Vallée and Morgan 2003; Rackin and Bachrach 2016). Empirical evidence supports the idea that fertility decision-making processes can be affected by early exposure to schemas, such as schemas that stress famialistic ideals and traditional gender roles as part of religious upbringing (Pearce and Davis 2016, p. 1433). Other research has found evidence consistent with the hypothesis that fertility intentions become more accurate in their predictions following key life course events, such as marriage and entry into motherhood (Rackin and Bachrach 2016).

The importance of considering life course processes has also been highlighted by Brehm and Schneider (2019), but a key feature of their approach is its acknowledgement that both partners are involved in fertility decision making. The Model of Dyadic Pathways (MDP) considers the shared experiences of the couple - i.e., the joint resources and behaviours and communication within the couple. The MDP allows an individual's fertility intentions to change as a result of his/her interactions with his/her partner. Moreover, the MDP aims to combine existing frameworks (TDIB, TPB, and CSM) in order to bring both reasoned and unreasoned action into studies of childbearing. For example, by allowing motivations to act directly on childbearing behaviour (bypassing intentions), Brehm and Schneider (2019, p. 17) allow for a 'laissez-faire pregnancy' in which 'a child is welcome, but neither intended nor unintended'.

The notion that there may be a degree of ambivalence in fertility intentions stems from the observation that significant proportions of the population are uncertain about how many children they intend to have; i.e., they respond to fertility intention questions with the answer 'do not know' (see, e.g., Berrington 2004; Morgan 1981; Ni Bhrolcháin and Beaujouan 2019). What is less clear is how to interpret this uncertainty. When asked a simple fertility inten- 
tions question such as 'Do you intend to have (any more) children?', respondents are likely to provide answers that lie on a continuum from a definite 'no' to a definite 'yes', and the proportion who say they are uncertain is often related to age and current parity. Ni Bhrolcháin and Beaujouan (2019) argued that although some individuals are indeed uncertain about their underlying childbearing preferences, those who actually have a positive preference may provide an uncertain answer because they feel unsure that these intentions will be realised. For example, an individual may be unsure about his/her biological ability to have children, or about whether s/he will have a suitable partner.

Evidence from the US suggests that young adults have generalised intentions based on factors such as fertility ideals developed through socialisation. As people move into their main reproductive ages, their uncertainty tends to increase. However, as individuals reach the end of their reproductive lives, uncertainty is once again reduced as they become 'too old' to have additional children (Morgan 1981). Evidence for women in the United Kingdom (UK) suggests a slightly different pattern, whereby the proportions who are uncertain are relatively high up to age 35, but decline after age 35 (Ni Bhrolcháin and Beaujouan 2019). The proportions who provide an uncertain answer can be large, and it is important that this category of response is not ignored by analysts (Morgan 1981). Among childless men and women aged 30 in the UK, around 20 per cent of both men and women gave the response 'don't know' when asked whether they were going to have children at some point in the future (Berrington 2017).

\section{FERTILITY INTENTIONS DYNAMICS OVER THE LIFE COURSE}

The availability of prospective longitudinal data, including repeated measurements of individuals' fertility intentions, has allowed demographers to examine how intentions change over the life course. Data from the National Longitudinal Study of Youth 1979 (NLSY79) have been used to examine the trajectories of fertility intentions among US women. Hayford (2009) demonstrated that expected family size at age 18 was relatively homogenous across groups, but that differences gradually emerged, producing larger differences in expected (and completed) fertility by age 40. Rybińska and Morgan (2019, p. 1571) showed that women from NLSY79 who ultimately remained childless followed two trajectories of intention: '(1) repeated postponement of childbearing and the subsequent adoption of a childless expectation at older ages or (2) indecision about parenthood signalled through vacillating reports of childless expectations across various ages'. This fluctuation in intended fertility is also highlighted by Gemmill (2019), who found that most permanently childless women had reported a positive expectation of having children at some point in their life course. The instability of intentions across the life course is likely attributable to the uncertainty in intentions, as was discussed in the previous section.

In the UK, two types of prospective longitudinal data have been used to examine the dynamics of fertility intentions across the life course. Consistent with Hayford's (2009) US findings, British birth cohort data also showed how intended family size drops between adolescence and young adulthood, and becomes more differentiated according to individuals' early life course experiences, such as their age at leaving full-time education and their employment experiences in young adulthood (Berrington and Pattaro 2014). Repeated measures of fertility intentions are also collected with UK national household panel surveys. Drawing on data from the British 
Household Panel Survey, Berrington (2004) and Iacovou and Travares (2011) showed that while some men and women make upward revisions of their intentions, they are more likely to report downward revisions. The proportions who revised their intentions were sizeable: six years after they were asked about their intended family size, only half of women aged 18-24 reported the same intention, with almost one-third having reduced it, and one-fifth having increased it (Berrington 2004). Iacovou and Travares (2011, p. 116) found that individuals often revised their intentions after separation and repartnering, after entering parenthood, and in response to their partner's expectations for childbearing. 'People whose partners expect more children than they do are more likely to revise upward; people whose partners expect fewer children than they do are more likely to revise downward.' As individuals approach the end of their reproductive lifespan, their intentions tend to be revised downwards. However, significant shares of childless men and women report having positive fertility intentions well into their 30s. As many of these individuals remain childless, the suggestion has been made that such people are 'perpetual postponers' (Berrington 2004, 2017).

\section{PREDICTIVE VALIDITY OF FERTILITY INTENTIONS}

The value of intentions as predictors of fertility has long been debated. At the individual level, stated intentions are significant statistical predictors of behaviour, and are often most closely associated with fertility outcomes, net of other factors (Berrington 2004; Régnier-Loilier et al. 2011; Schoen et al. 1999). However, data from NLSY79 (Morgan and Rackin 2010; Quesnel-Vallée and Morgan 2003), the British Birth Cohort Studies (Berrington 2017; Berrington and Pattaro 2014), and repeated panels such as the British Household Panel Survey (Berrington 2004) and GGS (Spéder and Kapitány 2015) have provided ample evidence of the mismatch between earlier stated fertility intentions and subsequent behaviour. Although some individuals exceed their intended family size, intentions remain unrealised in a greater number of cases. For example, almost one-third of childless British women born in 1970 who intended to have a child at age 30 remained childless at age 42 (Berrington 2017). Social scientists have attempted to explain this mismatch by either questioning the validity of the stated intention or discussing potential barriers to childbearing. According to Westoff and Ryder (1977), social desirability may prompt people who are uncertain to give a definite answer. Another explanation for this mismatch is that, especially where there is a long gap between the statement of intentions and outcomes, the intentions are modified in response to changing contingencies (Gemmill 2019; Trinitapoli and Yeatman 2018). While it has repeatedly been shown that intended family size decreases over the life course, whether such revisions result from changes in underlying preferences, or whether intentions are modified as a result of external constraints, remains unclear. If the latter is the case, then desires remain unfulfilled. The absence of a (suitable) partner has consistently been shown to be a key factor in the realisation of expectations (e.g., Berrington 2004; Berrington and Pattaro 2014; Hayford 2009; Quesnel-Vallée and Morgan 2003). Partnership formation, like childbearing, has been postponed to later ages. This postponement makes it harder for individuals to reach their reproductive goals, particularly given the decline in fecundability with age (Habbema et al. 2015). Women who start their childbearing at later ages have, on average, smaller completed family sizes (Berrington et al. 2015) as a result of this 'tempo-quantum' interaction (Kohler et al. 2002). 
Explanations for the postponement of childbearing (see Mills et al. 2011 for a review) are also explanations for unfulfilled fertility intentions. Following a process of postponement, childbearing plans 'can be easily diverted or superseded by other intentions drawing on other structures' (Bachrach and Morgan 2013, p 472). The gap between intended and realised fertility is often largest among the most educated women (Berrington and Pattaro 2014). Increased female education raises the age at leaving education, and results in women preferring to postpone parenthood until they are more established in their careers. Women's earnings increase the economic opportunity costs of reduced participation in the labour force to raise children. Institutional arrangements - e.g., subsidised child care or family-friendly employment policies that allow part-time work - can reduce the incompatibility of work and childrearing roles (Esping-Andersen and Billari 2015; Goldscheider et al. 2015; McDonald 2000). In Scandinavian countries, greater gender equity is associated with higher fertility, even though women's levels of participation in the labour market are high. In contrast, in Italy and Spain, gender equity in the public sphere - e.g., in higher education and employment - is not matched by gender equity in the home, as women are expected to take on the bulk of child care and domestic work. Thus, women postpone childbearing and often have no children, or limit their family size to just one child. Qualitative research examining the reasons that highly educated women in low fertility countries give for their fertility intentions has provided partial support for the gender equity theory (Brinton et al. 2018). Men and women interviewed in Spain did not talk about gender inequity directly. Instead, they highlighted that due to poor economic conditions, women were being forced to participate in the labour force in order to contribute to the household income. It thus appears that because men were unable to fulfil the breadwinning role, childbearing was postponed.

When permanently childless women in Britain were asked about their reasons for having no children, relatively few cited career reasons (Berrington 2017), while larger shares cited ill health, both related to infertility and to more general health. This finding raises the possibility that delaying childbearing in order to focus on educational and career opportunities may indirectly affect women's and (to a lesser extent) men's ability to fulfil their fertility intentions due to the increasing chances of poor health and sub-fecundity associated with age.

\section{FUTURE RESEARCH DIRECTIONS}

To understand the relationship between fertility intentions and their realisation at the micro and the macro levels, additional research is needed in a number of areas. First, a gendered perspective is currently lacking. Only a few studies have examined whether men's and women's intentions differ, or whether the factors affecting childbearing decision making vary by gender (e.g., Berrington 2017; Brinton et al. 2018; Iacovou and Travares 2011; Okun and Yurovich 2019; Puur et al. 2010). To examine whether gender inequity is a key factor in promoting the very low fertility levels seen in Europe, we need to be able to analyse information from men and women about gender roles in the public and the private spheres, and about work-family conflicts. Prospective data are required to examine whether the introduction of policies designed to reduce gender inequity actually have an impact on fertility. Moreover, future research needs to recognise the roles of both partners in reproductive decision making (Brehm and Schneider 2019). When data availability has allowed analyses to take a 'couple approach', greater insight into these roles has emerged. For example, such studies have shown that 
a woman's intentions can be revised in response to a new partner's intentions (Iacovou and Travares 2011), and that divergences in the male partner's and the female partner's intentions can constrain childbearing (Berrington 2004; Voas 2003).

Future studies of fertility behaviour should adopt a life course approach. But before this approach can be used, new prospective longitudinal data must be collected that provide repeated measures of intentions and perceived barriers to achieving these intentions; and multiple observations of people's other life circumstances, including their health, partnership, employment, and housing dynamics. It is only when they have such nuanced data that analysts can understand the effects of uncertainty and changes in other life course domains on childbearing intentions and their realisation. Ideally, cohorts should be followed from birth, with information being collected on, for example, parental socio-economic circumstances, parental demographic behaviour, childhood socialisation, and experiences in early adulthood. Such data would allow analysts to examine the inter-generational transmission of fertility behaviour, and the effect of early life course experiences on later intentions (Berrington and Pattaro 2014). Longitudinal studies such as the NLSY with annual or biennial measures of childbearing intentions have allowed researchers to model and predict longitudinal trajectories of childbearing intentions across the life course (Gemmill 2019; Rybińska and Morgan 2018).

Future studies need to better integrate the biological and social approach to fertility analyses (Mills and Tropf 2015). Family studies, and particularly twin studies, have demonstrated the heritability of childbearing behaviour. Motivations to have children are influenced not only by social factors, but by biological predispositions related to, for example, genetics, hormones, and neurological structures (Miller et al. 2010). Thus, future surveys should collect relevant biomarker and genetic data alongside social science data. Moreover, given the salience of health issues as reported barriers to the recuperation of fertility among childless postponers in the UK (Berrington 2017), more attention should be paid to the impact of physical and mental health on childbearing patterns.

Although fecundability tends to decline with age, especially after age 35 , there is significant individual heterogeneity in the likelihood of conceiving at older ages (Habbema et al. 2015). Thus, it is difficult for individuals and couples to predict the likelihood of having problems conceiving when they plan their future families. Ovarian reserve assessments are now offered by fertility clinics in many countries, and can be used by women with no known fertility problems to estimate their remaining reproductive lifespan (Birch Petersen et al. 2015). More research is needed that explores the characteristics of women and couples who seek fertility assessments, their motivations for doing so, and how this information alters their childbearing intentions and behaviour. In many countries, reproductive choices have been extended by new technologies such as oocyte freezing; and by legislative changes, such as reforms that allow single women to use sperm donors (Birch Petersen et al. 2015). Baldwin (2018) has argued that social egg freezing is being encouraged by neoliberal ideologies that make women feel responsible for their own fertility; i.e., that egg freezing is being promoted as a way of managing the risk of ovarian ageing. Studies have shown that women are often keen to find the right partner to have a(nother) child with, and that social egg freezing can be used to take pressure off new relationships, and to enable women to avoid 'panic partnering' (Inhorn et al. 2018). More research is needed on the use of oocyte freezing and of reproductive technologies such as IVF by unpartnered men and women, as well as by same-sex couples.

Finally, within demography, the majority of existing studies of fertility intentions and childbearing outcomes are based on the analysis of quantitative data. More qualitative studies 
in which individuals' voices are heard are needed if we are to understand the reasons why, for example, people postpone childbearing (Bernardi et al. 2008; Brinton et al. 2018), or decide to use reproductive technology (Baldwin 2018; Inhorn et al. 2018).

\section{ACKNOWLEDGEMENTS}

Ann Berrington's research is partly funded by the Economic and Social Research Council (Grant Ref: ES/R009139/1).

\section{NOTE}

1. Exceptions to this trend included the younger cohorts in Germany and Austria, who became the first groups to declare an ideal family size preference of around 1.7 in the 2001 Eurobarometer Survey (Goldstein et al. 2003).

\section{REFERENCES}

Ajzen, I. (1991), 'The theory of planned behaviour', Organizational Behaviour and Human Decision Processes, 50 (2), 179-211. doi:10.1016/0749-5978(91)90020-T.

Bachrach, C.A. and S.P. Morgan (2013), 'A cognitive-social model of fertility intentions', Population and Development Review, 39 (3), 459-85. doi:10.1111/j.1728-4457.2013.00612.x.

Baldwin, K. (2018), 'Conceptualising women's motivations for social egg freezing and experience of reproductive delay', Sociology of Health and Illness, 40 (5), 859-73. doi:10.1111/1467-9566.12728.

Beaujouan, É. and C. Berghammer (2019), 'The gap between lifetime fertility intentions and completed fertility in Europe and the United States: A cohort approach', Population Research and Policy Review, 38 (4), 507-35. doi:10.1007/s11113-019-09516-3.

Bernardi, L., A. Klärner, and H. von der Lippe (2008), 'Job insecurity and the timing of parenthood: A comparison between Eastern and Western Germany', European Journal of Population, 24 (3), 287-313. doi:10.1007/s10680-007-9127-5.

Berrington A. (2004), 'Perpetual postponers? Women's, men's and couple's fertility intentions and subsequent fertility behaviour', Population Trends, 117 (Autumn Issue), 9-19, accessed 1 January 2020 at http://eprints.soton.ac.uk/id/eprint/34148.

Berrington A. (2017), 'Childlessness in the UK', in M. Kreyenfeld and D. Konietzka (eds), Childlessness in Europe: Contexts, Causes and Consequences, Cham: Springer, pp. 57-76.

Berrington, A. and S. Pattaro (2014), 'Educational differences in fertility desires, intentions and behaviour: A life course perspective', Advances in Life Course Research, 21, 10-27. doi:10.1016/j.alcr .2013.12.003.

Berrington, A., J. Stone, and E. Beaujouan (2015), 'Educational differentials in timing and quantum of fertility: Evidence from 1940-1969 cohorts', Demographic Research, 33 (26), 733-54. doi:10.4054/ DemRes.2015.33.26.

Billari, F.C., D. Philipov, and M.R. Testa (2009), 'Attitudes, norms and perceived behavioural control: Explaining fertility intentions in Bulgaria', European Journal of Population, 25 (4), 439-65. doi:10 .1007/s10680-009-9187-9.

Birch Petersen, K., H.W. Hvidman, R. Sylvest, A. Pinborg, E.C. Larsen, K.T. Macklon, A. Nyboe Andersen, and L. Schmidt (2015), 'Family intentions and personal considerations on postponing childbearing in childless cohabiting and single women aged 35-43 seeking fertility assessment and counselling', Human Reproduction, 30 (11), 2563-74. doi:10.1093/humrep/dev237.

Bongaarts, J. and G. Feeney (1998), 'On the quantum and tempo of fertility', Population and Development Review, 24 (2), 271-91. doi:10.2307/2807974. 
Brehm, U. and N.F. Schneider (2019), 'Towards a comprehensive understanding of fertility: The model of dyadic pathways', Comparative Population Studies, 44, 3-36. doi:10.12765/CPoS-2019-01en.

Brinton, M.C. (2016), 'Intentions into actions: Norms as mechanisms linking macro-and micro-levels', American Behavioral Scientist, 60 (10), 1146-67. doi:10.1177/0002764216643130.

Brinton, M.C., X. Bueno, L. Oláh, and M. Hellum (2018), 'Postindustrial fertility ideals, intentions and gender inequality: A comparative qualitative analysis', Population and Development Review, 44 (2), 281-309. doi:10.1111/padr.12128.

Dommermuth, L., J. Klobas, and T. Lappegård (2011), 'Now or later? The theory of planned behaviour and timing of fertility intentions', Advances in Life Course Research, 16 (1), 42-53. doi:10.1016/j.alcr 2011.01.002.

Esping-Andersen, G. and F.C. Billari (2015), 'Re-theorizing family demographics', Population and Development Review, 41 (1), 1-31. doi:10.1111/j.1728-4457.2015.00024.x.

Eurostat (2019), 'Total fertility rate', accessed 1 January 2020 at https:/ec.europa.eu/eurostat/ databrowser/view/tps00199/default/table?lang=en.

Gemmill, A. (2019), 'From some to none? Fertility expectation dynamics of permanently childless women', Demography, 56 (1), 129-49. doi:10.1007/s13524-018-0739-7.

Goldscheider, F., E. Bernhardt, and T. Lappegård (2015), 'The gender revolution: A framework for understanding changing family and demographic behavior', Population and Development Review, 41 (2), 207-39. doi:10.1111/j.1728-4457.2015.00045.x.

Goldstein, J., W. Lutz, and M. R. Testa (2003), 'The emergence of sub-replacement family size ideals in Europe', Population Research and Policy Review, 22 (5), 479-96. doi:10.1023/B:POPU.0000020962 $.80895 .4 \mathrm{a}$.

Habbema, J.D.F., M.J. Eijkemans, H. Leridon, and E.R. te Velde (2015), 'Realizing a desired family size: When should couples start?', Human Reproduction, 30 (9), 2215-21. doi:10.1093/humrep/dev148.

Hayford, S. R. (2009), 'The evolution of fertility expectations over the life course', Demography, 46 (4), 765-83. doi:10.1353/dem.0.0073.

HFD (2019), Human Fertility Database, accessed 1 Jan 2020 at www.humanfertility.org.

Iacovou, M. and L.P. Tavares (2011), 'Yearning, learning and conceding: Reasons men and women change their childbearing intentions', Population and Development Review, 37 (1), 189-223. doi:10 $.1111 / \mathrm{j} .1728-4457.2011 .00391 . x$.

Inhorn, M. C., D. Birenbaum-Carmeli, J. Birger, L.M. Westphal, J. Doyle, N. Gleicher, D. Meirow, M. Dirnfeld, D. Seidmanm A. Kahane, and P. Patrizio (2018), 'Elective egg freezing and its underlying socio-demography: A binational analysis with global implications', Reproductive Biology and Endocrinology, 16 (1), 1-11. doi:10.1186/s12958-018-0389-z.

Johnson-Hanks, J.A., C.A. Bachrach, S.P. Morgan, and H.P. Kohler (eds) (2011), Understanding Family Change and Variation: Toward a Theory of Conjunctural Action, New York: Springer.

Klobas, J.E. and I. Ajzen (2015), 'Making the decision to have a child', in D. Philipov, A.C. Liefbroer and K.E. Klobas (eds), Reproductive Decision-Making in a Macro-Micro Perspective, Dordrecht: Springer, pp. 41-78.

Kohler, H.P., F.C. Billari, and J.A. Ortega (2002), 'The emergence of lowest-low fertility in Europe during the 1990s', Population and Development Review, 28 (4), 641-80. doi:10.1111/j.1728-4457 .2002.00641.x.

Lesthaeghe, R. (1995), 'The second demographic transition in Western countries: An interpretation', in K.O. Mason and A.M. Jensen (eds), Gender and Family Change in Industrialized Countries, Oxford: Clarendon Press, pp. 17-62.

Liefbroer, A.C. (2009), 'Changes in family size intentions across young adulthood: A life course perspective', European Journal of Population, 25 (4), 365-86. doi:10.1007/s10680-008-9173-7.

Liefbroer, A.C., K.E. Klobas, D. Philipov, and I. Ajzen (2015), 'Reproductive decision making in a macro-micro perspective: A conceptual framework', in D. Philipov, A.C. Liefbroer, and K.E. Klobas (eds), Reproductive Decision-Making in a Macro-Micro Perspective, Dordrecht: Springer, pp. 1-15.

McDonald, P. (2000), 'Gender equity in theories of fertility transition', Population and Development Review, 26 (3), 427-39. doi:10.1111/j.1728-4457.2000.00427.x.

Miller, W.B. (1994), 'Childbearing motivations, desires and intentions: A theoretical framework', Genetic, Social and General Psychology Monographs, 120 (2), 223-58. 
Miller, W.B., D.E. Bard, D.J. Pasta, and J.L. Rodgers (2010), 'Biodemographic modeling of the links between fertility motivation and fertility outcomes in the NLSY79', Demography, 47 (2), 393-414. doi: $10.1353 / \mathrm{dem} .0 .0107$.

Mills, M.C. and F.C. Tropf (2015), 'The biodemography of fertility: A review and future research frontiers', Kölner Zeitschrift für Soziologie und Sozialpsychologie, 67 (1), 397-424. doi:10.1007/ s11577-015-0319-4.

Mills, M.C., R.R. Rindfuss, P. McDonald, and E. te Velde (2011), 'Why do people postpone parenthood? Reasons and social policy incentives', Human Reproduction Update, 17 (6), 848-60. doi:10.1093/ humupd/dmr026.

Morgan, S.P. (1981), 'Intention and uncertainty at later stages of childbearing: The United States 1965 and 1970', Demography, 18 (3), 267-85. doi:10.2307/2060997.

Morgan, S.P. and H. Rackin (2010), 'The correspondence between fertility intentions and behavior in the United States', Population and Development Review, 36 (1), 91-118. doi:10.1111/j.1728-4457 .2010.00319.x.

Ni Bhrolcháin, M. and É. Beaujouan (2019), 'Do people have reproductive goals? Constructive preferences and the discovery of desired family size', in R. Schoen (ed.), Analytical Family Demography, Cham: Springer, pp. 27-56.

Okun, B.S. and L. Raz-Yurovich (2019), 'Housework, gender role attitudes and couples' fertility intentions: Reconsidering men's roles in gender theories of family change', Population and Development Review, 45 (1), 169-96. doi:10.1111/padr.12207.

ONS (2017), Data Set: Births by Parents' Characteristic, accessed 1 January 2020 at www.ons.gov.uk/ peoplepopulationandcommunity/birthsdeathsandmarriages/livebirths/datasets/birthsbyparentschara cteristics.

Pearce, L.D. and S.N. Davis (2016), 'How early life religious exposure relates to the timing of first birth', Journal of Marriage and Family, 78 (5), 1422-38. doi:10.1111/jomf.12364.

Philipov, D. (2009), 'Fertility intentions and outcomes: The role of policies to close the gap', European Journal of Population, 25 (4), 355-61. doi:10.1007/s10680-009-9202-1.

Puur, A., L.S. Oláh, M.I. Tazi-Preve, and J. Dorbritz (2010), 'Men's childbearing desires and views of the male role in Europe at the dawn of the 21st century', Demographic Research, 19 (56), 1883-912. doi:10.4054/DemRes.2008.19.56.

Quesnel-Vallée, A. and S.P. Morgan (2003), 'Missing the target? Correspondence of fertility intentions and behaviour in the US', Population Research and Policy Review, 22 (5-6), 497-525. doi:10.1023/ B:POPU.0000021074.33415.c1.

Rackin, H.M. and C.A. Bachrach (2016), 'Assessing the predictive value of fertility expectations through a cognitive-social model', Population Research and Policy Review, 35 (4), 527-51. doi:10.1007/ s11113-016-9395-z.

Régnier-Loilier, A., D. Vignoli, and C. Dutreuilh (2011), 'Fertility intentions and obstacles to their realization in France and Italy', Population, 66 (2), 361-89. muse.jhu.edu/article/463107.

Riederer, B., I. Buber-Ennser, and Z. Brzozowska (2019), 'Fertility intentions and their realization in couples: How the division of household chores matters', Journal of Family Issues, 40 (13), 1-23. doi: $10.1177 / 0192513$ X19848794.

Rybińska, A. and S.P. Morgan (2018), 'Childless expectations and childlessness over the life course', Social Forces, 97 (4), 1571-602. doi:10.1093/sf/soy098.

Schoen, R., N.M. Astone, Y.J. Kim, C.A. Nathanson, and J.M. Fields (1999), 'Do fertility intentions affect fertility behavior?', Journal of Marriage and Family, 61 (3), 790-9. doi:10.2307/353578.

Sobotka, T. and É. Beaujouan (2014), 'Two is best? The persistence of a two-child family ideal in Europe', Population and Development Review, 40 (3), 391-419. doi:10.1111/j.1728-4457.2014 .00691.x.

Spéder, Z. and B. Kapitány (2015), 'Influences on the link between fertility intentions and behavioural outcomes', in A.C. Liefbroer, K.E. Klobas, and D. Philipov (eds), Reproductive Decision-Making in a Macro-Micro Perspective, Dordrecht: Springer, pp. 179-212.

Testa, M.R. (2012), 'Family sizes in Europe: Evidence from the 2011 Eurobarometer survey', European Demographic Research Papers 2012, No. 2. Vienna Institute of Demography, Austrian Academy of Sciences. www.oeaw.ac.at/fileadmin/subsites/Institute/VID/PDF/Publications/EDRP/edrp_2012_02.pdf. 
Trinitapoli, J. and S. Yeatman (2018), 'The flexibility of fertility preferences in a context of uncertainty', Population and Development Review, 44 (1), 187-216. doi:10.1111/padr.12114.

Voas, D. (2003), 'Conflicting preferences: A reason fertility tends to be too high or too low', Population and Development Review, 29 (4), 627-46. doi:10.1111/j.1728-4457.2003.00627.x.

Westoff, C.F. and N.B. Ryder (1977), 'The predictive validity of reproductive intentions', Demography, 14 (4), 431-53. doi:10.2307/2060589.

Zeman, K., É. Beaujouan, Z. Brzozowska, and T. Sobotka (2018), 'Cohort fertility decline in low fertility countries: Decomposition using parity progression ratios', Demographic Research, 38 (1), 651-90. doi:10.4054/DemRes.2018.38.25. 